\title{
Perencanaan kawasan sempadan sungai Yeh Lating untuk pengembangan rekreasi berkelanjutan
}

\author{
I Kadek Dwitya Suma Hartadi ${ }^{1}$, Ni Wayan Febriana Utami1${ }^{*}$, I Gusti Alit Gunadi² \\ 1. Prodi Arsitektur Pertamanan, Fakultas Pertanian, Universitas Udayana, Indonesia \\ 2. Prodi Agroekoteknologi, Fakultas Pertanian, Universitas Udayana, Indonesia
}

*E-mail: wayan_febriana@unud.ac.id

\begin{abstract}
The planning of Yeh Lating riverscape area for sustainable recreation development. Recreation is an activity to fill any free time with non routine activities to get experiences that can bring satisfaction and entertainment. Sustainable recreation planning is a regional planning as place of recreation to meet current needs without compromising the future generations needs. Yeh Lating river in Kerambitan village is one of the potential river in south Kerambitan district, Tabanan regency. This river has been utilized by the surrounding community. However, no special arrangement has been planned as a recreation area, so planning is needed in this area. The method used in this study was field survey with an observation, questionnaires, interviews, and literature study technique. Stages of this study consist of inventory, analysed and synthesis which at the same time become the basic in planning. The results of this study showed that the available potentials in Yeh Lating River including an easy access and also facilities such as dams and beji, while the problems encountered in this study were the border physical problems, cleanliness, structuring, and lack of facilities such as parking. The concept of planning generated in this study was the concept of a combination between Balinese culture with the modern river. Suggestions that can be given was recommendation to the local government of Tabanan in the form of spatial zoning, accessibility, vegetation arrangement, and siteplan planning of Yeh Lating River.
\end{abstract}

Keywords: Kerambitan district, riverscape planning, sustainable recreation, Yeh Lating, water spring/beji

\section{Pendahuluan}

Kabupaten Tabanan adalah salah satu kabupaten dari sembilan kabupaten dan kota yang ada di Provinsi Bali. Kabupaten Tabanan terletak di bagian selatan Pulau Bali, memiliki luas wilayah $839,33 \mathrm{~km}^{2}$. Topografi Kabupaten Tabanan terletak di antara ketinggian 0 - $2.276 \mathrm{~m}$ dpl (Pemkab Tabanan, 2018). Salah satu kecamatan di Kabupaten Tabanan adalah Kecamatan Kerambitan dengan luas $42,39 \mathrm{~km}^{2}$ dan kepadatan penduduk sebesar 912 orang/ $/ \mathrm{km}^{2}$ (Kerambitan Dalam Angka, 2016). Kecamatan Kerambitan bagian utara memiliki kawasan rekreasi yaitu Bendungan Telaga Tunjung yang terletak di Desa Timpag. Sedangkan di bagian selatan Kecamatan Kerambitan belum tersedia ruang rekreasi sejenis, sehingga perlu adanya pengembangan kawasan bagian Kerambitan selatan.

Sungai Yeh Lating di kawasan Desa Kerambitan merupakan sungai potensial untuk dikembangkan sebagai kawasan rekreasi untuk masyarakat di bagian selatan Kecamatan Kerambitan. Sungai ini memiliki panjang $8000 \mathrm{~m}$ dan memiliki satu bendung yaitu Bendung Yeh Lating yang dibangun tahun 1981 (BPS, 2018). Sungai Yeh Lating di wilayah Desa Kerambitan memiliki potensi sebagai kawasan rekreasi. Sebelah timur sungai ini terdapat mata air yang bernama Beji Arasiga. Selain itu, lokasi sungai ini strategis karena berada di daerah dekat Puri Kerambitan-Tabanan yaitu Puri Anyar dan Puri Agung Kerambitan yang biasa dijadikan sebagai objek wisata. Sungai ini berada dekat jalur pariwisata menuju pantai Kelating dan pantai Pasut yang merupakan objek wisata alam. Observasi awal menunjukkan terdapat aktivitas masyarakat yang dilakukan di area sempadan Sungai Yeh Lating, seperti memancing, berjalan-jalan, dan upacara keagamaan. Namun, kebersihan merupakan masalah penting. Penataan dan pemanfaatan sungai sebagai kawasan rekreasi diharapkan dapat memberikan nilai tambah secara ekonomis maupun ekologis bagi masyarakat sekitar, serta memperindah tampilan fisik sungai. Oleh sebab itu, maka penelitian ini perlu dilakukan dengan tujuan untuk membangun konsep dan zona yang dapat diterapkan pada kawasan sempadan Sungai Yeh Lating dengan 
hasil akhir berupa siteplan Sungai Yeh Lating. Sehingga hasil yang diperoleh dari penelitian diharapkan bermanfaat dalam menghasilkan rekomendasi untuk menata sempadan sungai yang ada di Kabupaten Tabanan, khususnya sempadan Sungai Yeh Lating.

\section{Metode Penelitian}

\subsection{Lokasi Penelitian}

Lokasi penelitian adalah kawasan Sungai Yeh Lating, Desa Kerambitan, Kecamatan Kerambitan, Kabupaten Tabanan, Provinsi Bali (Gambar 1).

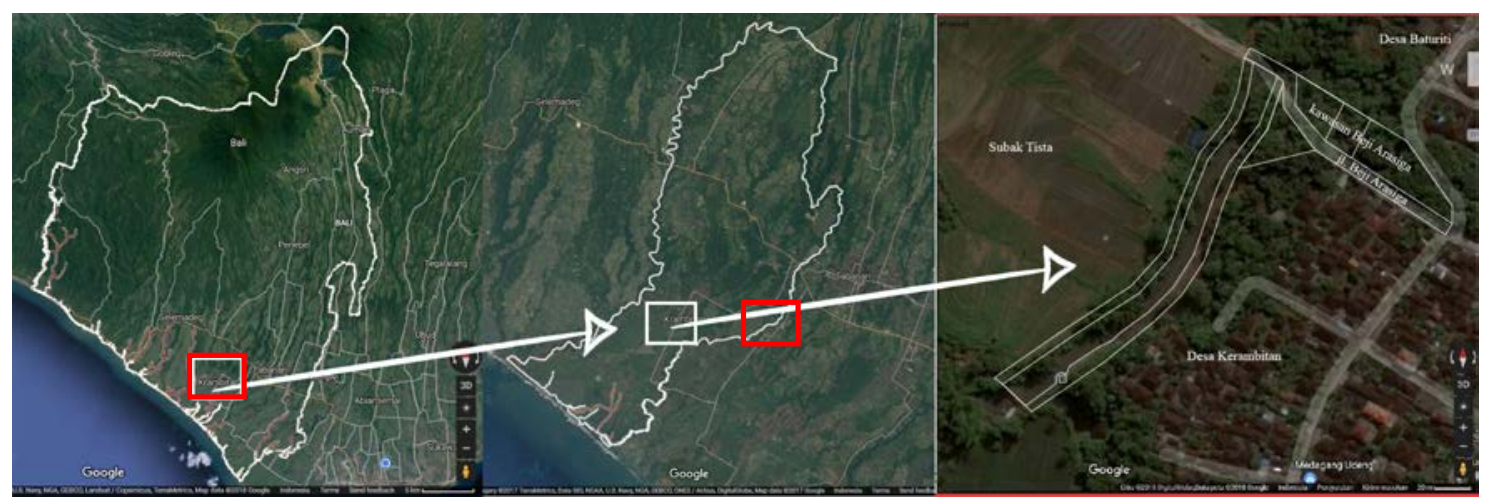

Gambar 1. Lokasi Penelitian

Sumber: Google Maps, dengan pengolahan.

\subsection{Alat dan Bahan}

Alat dan bahan yang digunakan di penelitian ini yaitu alat tulis, kamera, lembar wawancara, lembar kuisioner dan komputer dengan software AutoCAD, Photosop, Microsoft Word, Microsoft Excel.

\subsection{Metode Penelitian}

Metode penelitian yang digunakan adalah metode survei. Menurut Ali (2014) survei pada dasarnya merupakan pemeriksaan secara teliti tentang fakta atau fenomena perilaku dan sosial terhadap subyek dalam jumlah besar. Metode survei yang dilakukan dimulai dari tahapan pengumpulan data, analisis data dan kemudian menghasilkan sintesis yang digunakan sebagai dasar konsep perencanaan.

\subsection{Metode Pengumpulan Data}

Tahapan pengumpulan data dilakukan dengan beberapa tehnik yaitu observasi, wawancara, studi kepustakaan, dan pembagian kuesioner sebanyak 40 sampel yang dipilih secara purposive sample. Jenis data yang dikumpulkan dalam penelitian ini berupa data primer dan data sekunder. Data primer berupa pengumpulan data yang diperoleh melalui pengamatan langsung di lapangan dengan melakukan observasi, wawancara dan kuesioner. Sedangkan data sekunder merupakan data yang diperoleh dari pustaka dan sumber tertulis mencakup studi pustaka dari buku-buku, jurnal, majalah yang berkaitan tentang Sungai Yeh Lating, dan media internet yang berkaitan tentang Sungai Yeh Lating. Data yang telah dikumpulkan kemudian dilanjutkan ke tahanpan analisis dan sintesis data.

\subsection{Metode Analisis dan Tahapan Penelitian}

Data dan informasi yang telah diperoleh dari hasil observasi, wawancara, kuesioner maupun studi pustaka dianalisis baik secara deskriptif dan spasial. Analisis yang dilakukan meliputi faktor pendukung baik dari segi ekologi maupun sosial di lokasi penelitian. Hasil dari pengumpulan data kemudian disusun agar mudah dipahami untuk mencari kesesuaian pengembangan yang digunakan sebagai landasan perencanaan.

Tahapan penelitian dimulai dari inventarisasi di lokasi penelitian untuk mencari data tentang vegetasi, satwa, aspek sosial masyarakat, dan kondisi umum tapak. Hasil inventarisasi kemudian dianalisis untuk menemukan potensi, kendala dan kesesuaian tapak untuk pengembangan. Hasil analisis kemudian digunakan sebagai dasar konsep pengembangan. Konsep yang sudah dikembangkan digunakan sebagai konsep perencanaan dengan hasil berupa pembagian zona dan sirkulasi serta siteplan Sungai Yeh Lating sebagai kawasan rekreasi. Berikut bagan tahapan penelitian yang dilakukan. 


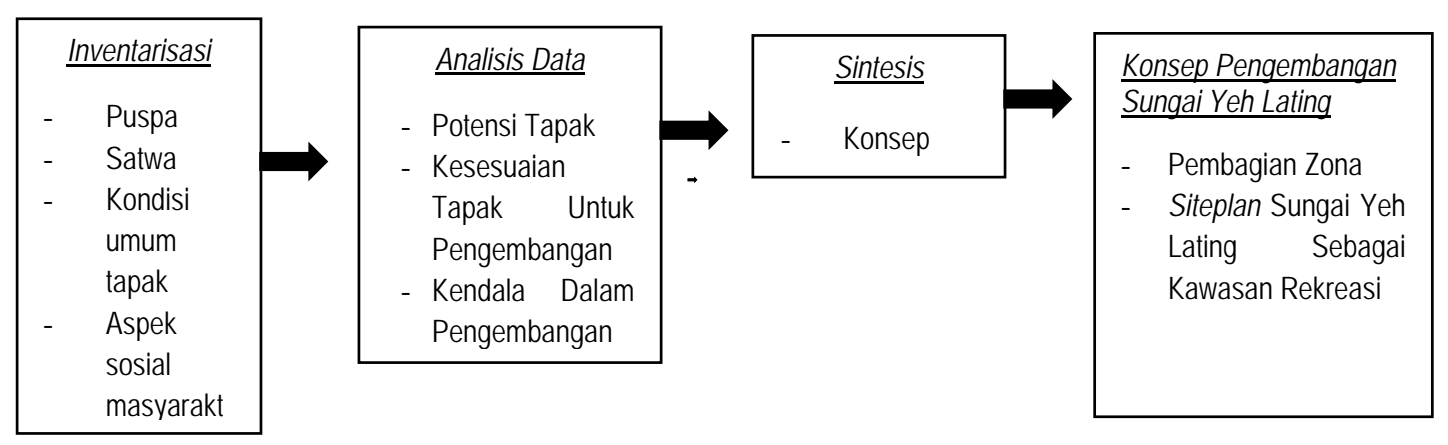

Gambar 2. Tahapan Penelitian

\subsection{Batas Wilayah Studi}

Lokasi penelitian dilakukan di Sungai Yeh Lating, Desa Kerambitan, Kecamatan Kerambitan, Kabupaten Tabanan dengan melakukan perencanaan kawasan sempadan sungai sepanjang $242 \mathrm{~m}$. Batas lokasi bagian selatan adalah Bendung Yeh Lating memanjang $242 \mathrm{~m}$ ke arah utara hingga jembatan yang menghubungkan Desa Kerambitan dengan Desa Tista. Area barat di lokasi penelitian berbatasan dengan persawahan sedangkan area timur berbatasan dengan kebun dan pemukiman warga. Bagian utara area penelitian berbatasan dengan Desa Baturiti, Kerambitan. Sedangkan bagian barat dan selatan area penelitian berbatasan dengan Desa Tista. Kawasan Beji Arasiga seluas $2.192 \mathrm{~m}^{2}$ di bagian timur jembatan termasuk dalam batas penelitian. Luas seluruh kawasan penelitian adalah $9.799 \mathrm{~m}^{2}$. Objek yang dikaji adalah kondisi fisik, biofisik, dan sosial kawasan Sungai Yeh Lating di Desa Kerambitan. Hasil akhir dari penelitian adalah rencana kawasan dan zona ruang yang berupa siteplan.

\section{Hasil dan Pembahasan}

\subsection{Gambaran Umum}

Sungai Yeh Lating merupakan salah satu dari 26 sungai yang ada di Kabupaten Tabanan. Sungai ini memiliki panjang $8 \mathrm{~km}$ dan memiliki satu bendung yang bernama Bendung Yeh Lating. Bendung ini dibangun pada tahun 1981 (Hartania, 2016). Sekitar sungai terdapat mata air yang dimanfaatkan sebagai beji. Beji merupakan pancuran air suci yang digunakan upacara keagamaan hindu di bali. Perkerasan pada beji ini dibangun tahun 1983. Kondisi lantai beji berlumut dan Apit surang (gapura) pada area beji rusak pada bagian ujungnya. Sejak awal lantai dasar beji ini berada di bawah permukaan sempadan sungai sehingga saat air sungai tinggi, lantai dasar beji tergenang air.

\subsection{Biofisik}

\subsubsection{I lim}

Berdasarkan data dari pengamatan oleh Badan Meteorologi Klimatologi dan Geofisika III (BMKG III), curah hujan bulanan di lokasi penelitian selama lima tahun (2013-2017) memiliki rata-rata 197,90 mm. Intensitas hujan terendah adalah $0 \mathrm{~mm}$ pada bulan September 2014, sedangkan intensitas curah hujan tertinggi adalah $525 \mathrm{~mm}$ pada bulan Februari 2017. Suhu udara di lokasi penelitian berkisar antara $25,6{ }^{\circ} \mathrm{C}$ sampai $29,0^{\circ} \mathrm{C}$ dengan rata-rata adalah $27,45^{\circ} \mathrm{C}$. Kelembaban udara bulanan di lokasi penelitian berkisar dari $75 \%$ sampai $85 \%$ dengan rata-rata adalah 79,88\%. Kecepatan angin rata-rata di lokasi penelitian sebesar 6,25 knot dengan rentang kecepatan angin antara tiga sampai sembilan knot dengan arah angin rata-rata berasal dari timur.

\subsubsection{Puspa dan Satwa}

Berdasarkan hasil pengamatan di tapak penelitian, terdapat beberapa macam vegetasi antara lain talas (Colocasia esculenta), pisang batu (Musa balbisiana), daun ungu (Graptophyllum Pictum L. Griffith), kelapa hijau (Cocos nucifera), pinang (Areca catechu), dan widelia (Sphagneticola trilobata) yang beberapa diantaranya tumbuh liar. Hasil observasi di tapak penelitian belum terlihat adanya penataan yang jelas, sehingga perlu adanya perencanaan dalam proses penataan vegetasi mengingat kebutuhan cahaya, air dan kelembaban tanamanan yang berbeda. 
Menurut hasil wawancara terbuka dengan pengunjung yang sedang memancing, ikan yang sering didapatkan di sungai Yeh Lating adalah ikan nyalian atau seluang (Rasbora sp), nilem (Osteochilus vittatus), dan tawes (Barbonymus gonionotus). Namun, kadang bisa mendapatkan ikan nila (Oreochromis niloticus), karper (Cyprinus carpio), dan lele (Clarias sp) dalam ukuran yang cukup besar. Aktivitas berburu hewan yang dilakukan warga sekitar. Sasaran buruan antara lain tupai (Scandentia sp) dan biawak (Varanus sp). Hewan ini diburu untuk dikonsumsi karena dianggap hama, sedangkan sebangsa burung seperti tekukur (Spilopelia chinensis) dan punai (Treon sp) tidak boleh diburu karena tidak mengganggu dan dianggap memberi kenyamanan bagi masyarakat.

\subsubsection{Hidrologi}

Kondisi air di Sungai Yeh Lating berwarna coklat dan dipenuhi dengan sampah organik maupun non organik, berbanding terbalik dengan dengan kondisi air di Beji Arasiga yang bening. Menurut data dari Badan Pusat Statistik, debit air sungai $0.507 \mathrm{~m}^{3} / \mathrm{det}$. Hasil pengamatan di lapangan kenaikan permukaan air naik saat turun hujan tiga hari berturut turut sekitar $30 \mathrm{~cm}$. Selama pengamatan kenaikan air saat hujan belum pernah sampai meluap melewati sempadan

\subsubsection{Tanah}

Lokasi penelitian terletak pada dataran rendah dengan ketinggian $\pm 100 \mathrm{~m}$ dpl dengan kemiringan 12,86\%. Data dari Peta Tanah Tinjau Pulau Bali 1970 menunjukkan jenis tanah di Desa Kerambitan yaitu latosol coklat kekuningan (Bappeda Tk. II, 2015). Tanah latosol dengan warna coklat ini memiliki permeabilitas dan agregat yang tinggi serta memiliki kepekaan terhadap erosi yang rendah. Tingkat kepekaan erosi yang rendah dapat membuat tanah tidak mudah terkikis oleh arus sungai.

\subsubsection{Aksebilitas}

Akses menuju tapak tergolong mudah dengan kondisi jalan menggunakan paving stone dari jalan Beji Arasiga sampai ke jembatan menuju Desa Tista yang menjadi batas utara lokasi penelitian. Area yang bisa dilewati oleh kendaraan hanya pada bagian jalan Beji Arasiga dan sempadan Sungai Yeh Lating. Sedangkan sirkulasi manusia bisa mengakses seluruh bagian tapak. Kondisi di jalan pada sempadan Sungai Yeh Lating masih berupa tanah sehingga becek saat musim hujan.

\subsubsection{Kondisi Sempadan}

Sempadan dibagi menjadi dua yaitu sempadan bagian barat dan sempadan bagian timur. Sempadan di bagian timur menggunakan perkerasan beton untuk menjaga tanah sedangkan pada sempadan bagian barat masih alami.

\subsubsection{Kondisi Beji (Pancuran Air Suci)}

Beji Arasiga merupakan beji yang memiliki tiga tingkatan pancuran, perkerasannya dibangun pada tahun 1983. Tingkat pertama merupakan tingkat yang biasa digunakan untuk upacara keagamaan yang terletak di posisi tengah. Tingkat dua dan tiga terletak di bagian kiri dan kanan dan merupakan pancoran yang biasa digunakan masyarakat untuk mandi. Kondisi lantai di Beji Arasiga banyak ditumbuhi lumut. Kawasan Beji Arasiga hanya memiliki sedikit vegetasi berupa rumput, kamboja dan cempaka.

\subsection{Sosial}

Aktivitas masyarakat di tapak penelitian antara lain memancing, mandi, dan melakukan upacara keagamaan. Banyak anak-anak yang datang ke area sungai, tetapi belum adanya fasilitas permainan. Aktivitas anak-anak ini berbahaya mengingat tidak adanya pembatas atau pagar di sempadan sungai. Perlu adanya pembangunan area bermain dan pagar pembatas untuk membatasi area bermain anak dan menghindarkan anak dari resiko terjatuh ke sungai.

\subsubsection{Aktivitas Pengguna}

Hasil dari tabulasi kunjungan didominasi oleh laki-laki dengan intensitas kunjungan antara dua sampai lima orang secara bersamaan. Alat transportasi yang digunakan pengunjung adalah kendaraan roda dua dan para pengunjung parkir sembarangan di pinggir jalan sehingga mengganggu pengguna jalan. Perlu adanya perencanaan tempat parkir khusus yang mudah dijangkau agar kendaraan lebih tertata dan tidak mengganggu aksebilitas.

\subsubsection{Kunjungan oleh Pengguna}

Jumlah pengunjung dalam sehari berkisar 10 sampai 30 orang perhari. Rentang usia pengunjung antara 6 sampai 70 tahun. Aktivitas rata-rata pengunjung adalah memancing dan upacara keagamaan. 
Pengunjung paling banyak saat upacara keagamaan di Beji Arasiga karena melibatkan ratusan orang di areal beji sampai ke sempadan sungai untuk upacara tersebut.

\subsubsection{Perilaku Pengguna}

Erosifitas dan perilaku manusia di daerah hulu sangat berpengaruh pada kualitas fisik air sungai. Dampak yang diakibatkan seperti pendangkalan karena banyak sampah, air menjadi sangat keruh, sampah menyumbat aliran air, dan mengurangi keindahan lingkungan dan kesucian kawasan Beji Arasiga. Berbagai upaya yang dilakukan pemerintah khususnya perangkat desa antara lain memberikan sosialisasi kepada masyarakat pendamping sungai tersebut, pembangunan jalan dan tanggul di sisi timur sungai, melakukan pemungutan sampah keliling desa. Sulit menagani pencemaran lingkungan tanpa adanya kesadaran dari masyarakat itu sendiri. Pencemaran lingkungan dapat diatasi dengan perencanaan lingkungan, namun dampak perencanaan lingkungan ini lama dan bertahap. Perencanaan lingkungan di Sungai Yeh Lating khususnya kawasan Beji Arasiga harus dilakukan dengan berkoordinasi dengan desa tetangga seperti Desa Baturiti dan Desa Tista.

\subsection{Sintesis}

\subsubsection{Konsep Dasar}

Konsep dasar yang digunakan untuk sempadan sungai Yeh Lating di kawasan Beji Arasiga Desa Kerambitan adalah sungai yang mengombinasikan terasering pada subak di Bali dengan sungai kekinian. Sungai kekinian yang dimaksud merupakan konsep sungai yang populer di masa kini atau masa sekarang. Konsep ini dipilih sesuai dengan Perda Tabanan No 11 Tahun 2012. Menurut Perda No. 11 Tahun 2012 RTRW Kabupaten Tabanan (2012-2032), ruang wilayah di Kabupaten Tabanan perlu dikembangkan secara lestari, aman, nyaman, produktif dan berkelanjutan berlandaskan kebudayaan bali sesuai dengan falsafah Tri Hita Karana.

\subsubsection{Konsep Pengembangan}

Pengembangan Sungai Yeh Lating di kawasan Desa Kerambitan terinspirasi dari terasering pada subak di Bali yang dikombinasikan dengan sungai kekinian. Konsep terasering sawah di Bali yang memiliki sistem subak yang terkenal menginspirasi pembentukan sempadan bagian barat. Konsep ini juga memperkuat karakter Kabupaten Tabanan dengan julukan lumbung padi pulau dewata. Sedangkan konsep kekinian menggunakan bentuk sungai kekinian dengan ciri simpel berupa pemasangan dinding penyangga pada sempadan sungai dan penambahan pagar pembatas, simpel dan terlihat menyatu dengan pemukiman warga, bentuk ini juga memerlukan anggaran dana yang lebih sedikit mengingat sudah adanya perkerasan di sempadan bagian timur.

Pemilihan kombinasi antara terasering sawah di Bali pada subak dengan sungai kekinian ini mencirikan perkembangan jaman di Bali antara masalalu yang identik dengan pertanian dengan masa kini yang identik dengan pariwisata modern. Konsep Tri Hita Karana yaitu hubungan manusia dengan tuhan dicirikan dengan aktivitas upacara keagamaan di area suci di Beji Arasiga, hubungan manusia dengan manusia diaplikasikan dengan dibuatnya area rekreasi sehingga manusia bisa saling berinteraksi, hubungan manusia dengan alam dicirikan dengan perencanaan kawasan sungai yang bertujuan untuk mengurangi pencemaran yang ada sehingga bisa dikelola secara berkelanjutan.

\subsubsection{Penataan Ruang}

Penataan ruang mengikuti pola sungai yang dibagi menjadi lima zona yaitu beji, parkir, taman bermain, dan sempadan (Gambar 3). Pembagian zona diperhitungkan sesuai keperluan pengunjung di lokasi penelitian. Fasilitas tambahan disesuaikan dengan kebutuhan zona yang ditentukan. Model fasilitas di zona yang ada disesuaikan dengan keperluan di masing-masing zona adalah sebagai berikut: 


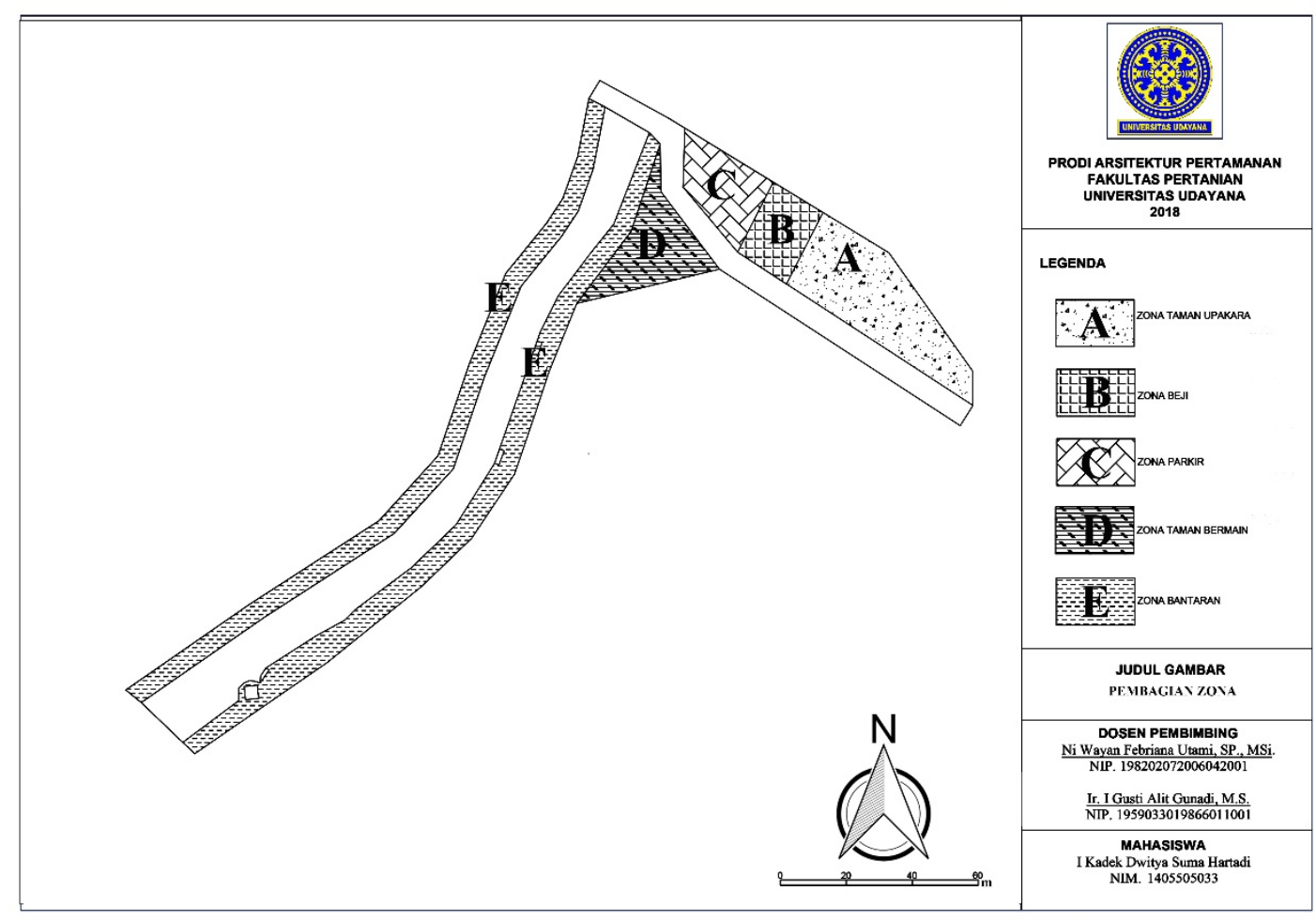

Gambar 3. Pembagian zona

\section{a. Zona Taman Upakara}

Zona taman upakara merupakan zona yang bertujuan untuk mempermudah masyarakat Desa Kerambitan dalam mencari tanaman yang akan diperlukan saat melakukan upacara. Luas zona yang direncanakan pada area ini adalah $1.249 \mathrm{~m}^{2}$. Rekomendasi penutup tanah di area ini adalah koral agar tidak terlalu banyak debu pada musim kemarau dan tetap ada resapan pada musim hujan. Penambahan fasilitas steping stone direkomendasikan dengan paving stone. Taman upakara ini juga bisa digunakan sebagai media pembelajaran untuk pengetahuan tentang tanaman yang dipergunakan untuk upacara keagamaan, sehingga masyarakat yang tidak tahu bisa menjadi tahu tentang prasarana upacara keagamaan. Pemilihan lokasi taman upakara adalah pada tempat paling depan dan tertinggi di area tapak

\section{b. Zona beji}

Perencanaan di zona beji adalan zona yang bertujuan sebagai tempat mengaplikasikan Tri Hita Karana yaitu hubungan manusia dengan tuhan. Zona ini tidak terlalu memerlukan penambahan fasilitas karena areal beji dipergunakan oleh masyarakat untuk upacara pembersihan. Luas area beji yang direncanakan adalah 422 m2. Rencana yang sudah ada dari pihak desa sebatas peninggian posisi pancuran dan lantai beji sehingga tidak tergenang saat air sungai naik. Untuk penutup tanah direkomendasikan menggunakan koral agar mempercepat resapan air dan menghindari lantai licinkarena ditumbuhi lumut.

\section{c. Zona parkir}

Zona parkir yang direncanakan diletakan di sebelah barat Beji Arasiga seluas 524 m2. Pemilihan lokasi ini karena lokasi ini paling dekat menuju zona lainnya dan mudah untuk dijangkau. Parkir motor dan mobil digabung menjadi satu lokasi dengan pembagian setengah bagian utara dan timur untuk motor dan bagian selatan untuk mobil. Pertimbangan yang diambil adalah untuk mengefesiensi tapak karena bisa digunakan mobil maupun motor, dan mempermudah dalam pemantauan areal parkir. Perkerasan yang direkomendasikan pada area ini adalah grass block. Perkerasan beton dipilih karena lebih kuat menahan kendaraan. Fasilitas yang diperlukan di zona ini adalah kamar kecil, pos parkir dan garis batas parkir. Penempatan kamar kecil di zona ini karena zona ini mudah dijangkau dari zona lainnya dan posisinya yang tidak lebih tinggi dari posisi Beji Arasiga yang direncanakan. 
d. Zona taman bermain

Zona bermain bertujuan untuk menyediakan ruang bermain yang aman kepada anak-anak mengingat bahaya saat bermain di sungai. Luas yang direncanakan pada zona ini adalah $663 \mathrm{~m} 2$. Pemilihan lokasi untuk zona ini karena mudah untuk dipantau dan lokasi ini merupakan lokasi yang paling gampang untuk dituju dari tempat parkir. Perkerasan yang direkomendasikan pada zona ini adalah grass block. Grass block dipilih karena selain bisa memberikan kesan yang berbeda dengan sempadan juga tetap menjaga agar air hujan tetap meresap ke tanah. Fasilitas yang perlu ditambahkan di zona ini adalah sarana permainan seperti ayunan, perosotan, dan jungkat jungkit serta kantin. Alasan rekomendasi penambahan kantin di area ini adalah karena zona ini berada di tempat yang mudah dijangkau dari semua zona. Penambahan fasilitas seperti kantin bambu minimalis ini diperlukan untuk memanjakan pengunjung, tetapi bentuk warung yang dipilih sebaiknya menggunakan konsep ramah lingkungan dengan bambu dan barang yang dijual sebaiknya makanan khas setempat agar bisa menjadi daya tarik bagi pengunjung. Warung ini sebaiknya dikelola oleh desa dengan pengambilan retribusi kepada penjual. Tujuannya agar uang retribusi bisa digunakan untuk biaya perawatan agar tapak bisa digunakan secara berkelanjutan. Selain bisa menjadi daya tarik juga bisa memberi keuntungan ekonomi bagi masyarakat yang berjualan di sana.

e. Zona sempadan

Zona sempadan merupakan zona penting yang memerlukan fasilitas dan model perencanaan yang baik. Zona yang direncanakan seluas $2.898 \mathrm{~m} 2$ di bagian timur dan barat aliran sungai. Area sempadan dapat difungsikan sebagai tempat bersantai. Pengembangan dilakukan bertujuan untuk menata dan meningkatkan potensi dari sungai ini. Konsep awal tentang kombinasi, salah satu ciri khas dari sawah bali yaitu terasering perlu diaplikasikan. Sempadan direncanakan dengan dua konsep berbeda. Sempadan bagian barat diaplikasikan konsep terasering agar terlihat menyatu dengan sawah yang tepat ada di bagian barat sempadan ini. Penambahan perkerasan berupa beton ditambahkan di tangga terasering agar tanah tidak longsor seperti yang diplikasikan di Sungai Badung. Perencanaan ini dilakukan untuk memperkental nuansa sawah yang ada di kawasan sungai ini. Sedangkan untuk perencanaan sempadan bagian di timur menggunakan gaya modern dengan perkerasan beton pada sempadan seperti yang sudah diaplikasikan di Sungai Epicentrum Jakarta. Perencanaan gaya ini dipilih karena mengingat sudah adanya tanggul di sempadan bagian timur, sehingga bisa menekan anggaran. Alasan lainnya adalah karena dekat dengan rumah warga sehingga jika rencana ini diaplikasikan, tidak akan terlalu mencolok antara sempadan ini dengan rumah warga. Fasilitas seperti gazebo sebaiknya juga ditambahkan di sempadan timur. Gazebo bisa digunakan untuk sekedar bersantai sambil melihat hamparan sawah. Gazebo juga bisa memberi nilai tambah pada musim layang-layang karena arah angin rata - rata berasal dari timur ke barat, sehingga tempat ini bisa menjadi tempat bersantai sambil melihat layang-layang yang dimainkan di sawah. Permainan layang-layang ini bisa menjadi atraksi dan daya tarik bagi pengunjung. Rekomendasi pemilihan material di jalan yang ada di sempadan sebaiknya menggunakan paving stone agar terlihat rapi. Penambahan pagar di sempadan bagian timur diperlukan untuk memberikan keamanan bagi pengunjung.

\subsubsection{Penataan Sirkulasi}

Penataan sirkulasi dibagi menjadi dua yaitu sirkulasi manusia dan sirkulasi kendaraan. Sirkulasi manusia menggunakan sirkulasi radial. sirkulasi manusia bisa ke semua zona yang ada dengan titik pusat jalan Beji Arasiga. Menurut Simonds (2006), sirkulasi radial memiliki ciri adanya titik pusat yang menjadi tujuan atau asal pergerakan di jalan-jalan sekitarnya. Sirkulasi kendaraan menggunakan sirkulasi linier. Sirkulasi linier merupakan sirkulasi yang bergerak terus menerus dalam satu arah atau lebih. Sirkulasi kendaraan hanya sebatas di Jalan Beji Arasiga dan di area parkir (Gambar 4). 


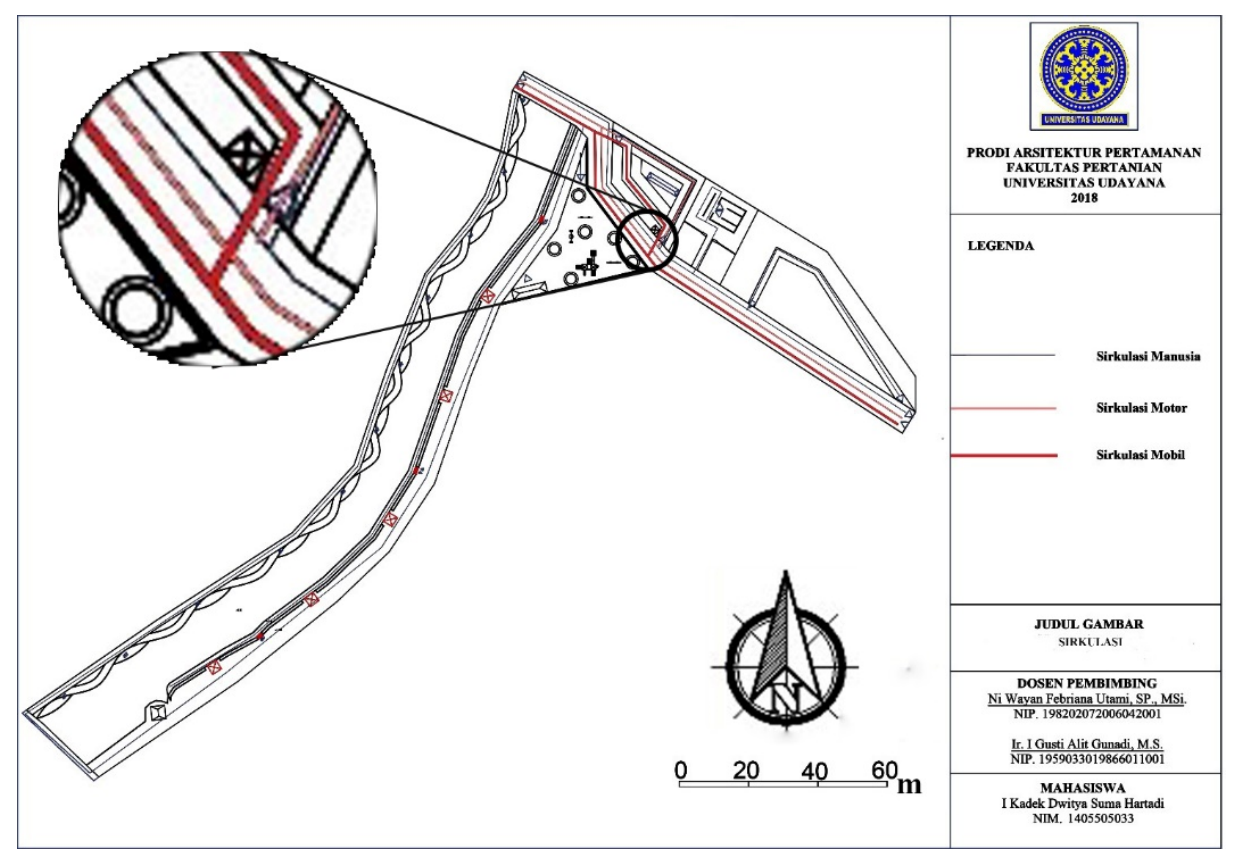

Gambar 4. Penataan Sirkulasi

\subsubsection{Penataan Vegetasi}

Penaataan vegetasi mengutamakan tanaman eksisting yang ada. Pemilihan tanaman ini menyesuaikan dengan ketahanan tanaman pada tapak penelitian. Tanaman yang direkomendasikan menggunakan tanamanan eksisting yang ada, kecuali pada taman upakara yang ditambahkan tanaman dari luar tapak agar koleksi tanaman lebih lengkap. Pemilihan tanaman semak tidak terlalu banyak mengingat lokasi penelitian merupakan tempat hidup satwa berbahaya seperti ular. Pemilihan tanaman melihat dari ketahanan, estetika dan merupakan tanaman eksisting yang diutamakan.

Tanaman yang diperlukan di tanaman upakara adalah tanaman yang digunakan dalam upacara keagamaan di kawasan Desa Kerambitan. Rekomendasi tanaman yang diperlukan di zona ini seperti Kelapa (Cocos nucifera), Pisang (Musa sp), Bambu (Bambusa sp), Palem Wregu (Rhapis excelsa), Ancak (Ficus rumphii), dan Beringin (Ficus benjamina). Perencanaan penanaman di zona beji perlu diperhitungkan dengan baik. Tanaman peneduh yang direkomendasikan di zona beji menggunakan tanaman eksisting yang ada yaitu tanaman kamboja (Plumeria sp) dan cempaka (Magnolia champaca) agar saat melakukan upacara bisa lebih teduh dan masih menyisakan tempat yang luas untuk berteduh di bawahnya. Tanaman peneduh seperti flamboyan (Delonix regia) diperlukan di zona bermain untuk menambah kenyamanan bermain anak. Tanaman pembatas juga ditambahkan di bagian pinggir bagian utara dan timur zona bermain. Tanaman pembatas yang digunakan adalah tanaman kembang sepatu (Hibiscus rosa-sinensis). Tanaman yang direkomendasikan sebagai peneduh di zona parkir adalah tanaman waru (Hibiscus tiliaceus) karena tidak mengenal musim atau evergreen. Tanaman waru (Hibiscus tiliaceus) memiliki buah yang kecil sehingga jika jatuh tidak berbahaya bagi kendaraan. Buah dari tanaman waru (Hibiscus tiliaceus) juga tidak diamakan oleh burung sehingga mengurangi potensi kotoran burung yang jatuh di kendaraan. Pemilihan tanaman pada area bantaran bagian barat direkomendasikan dengan tanaman pinang (Areca catechu) dan penutup tanah menggunakan rumput jepang (Pennisetum purpureum schamach). Sedangkan area sempadan bagian timur menggunakan tanaman peneduh berbunga yaitu tanaman kamboja (Plumeria sp) dengan penutup tanah widelia (Sphagneticola trilobata).

\subsubsection{Siteplan}

Siteplan merupakan gambar dua dimensi yang menunjukan rencana detail sebuah tapak yang sudah direncanakan. Pembentukan konsep dan perencanaan fasilitas pendukung dari sebuah tapak harus diperhitungkan. Pemilihan tanaman harus memperhitungkan ketahanan dan kecocokan pada tapak. Kesesuaian terhadap iklim, kelembaban, sinar matahari harus diperhitungkan untuk menghindari 
ketidakcocokan. Pemilihan tanaman eksisting sangat disarankan karena memiliki ketahanan lebih terhadap tapak yang akan direncanakan. Hasil perencanaan dari konsep, zonasi, pemilihan fasilitas dan vegetasi dibuat menjadi siteplan. Siteplan dari tapak Sungai Yeh Lating Desa Kerambitan dapat dilihat pada Gambar 5.

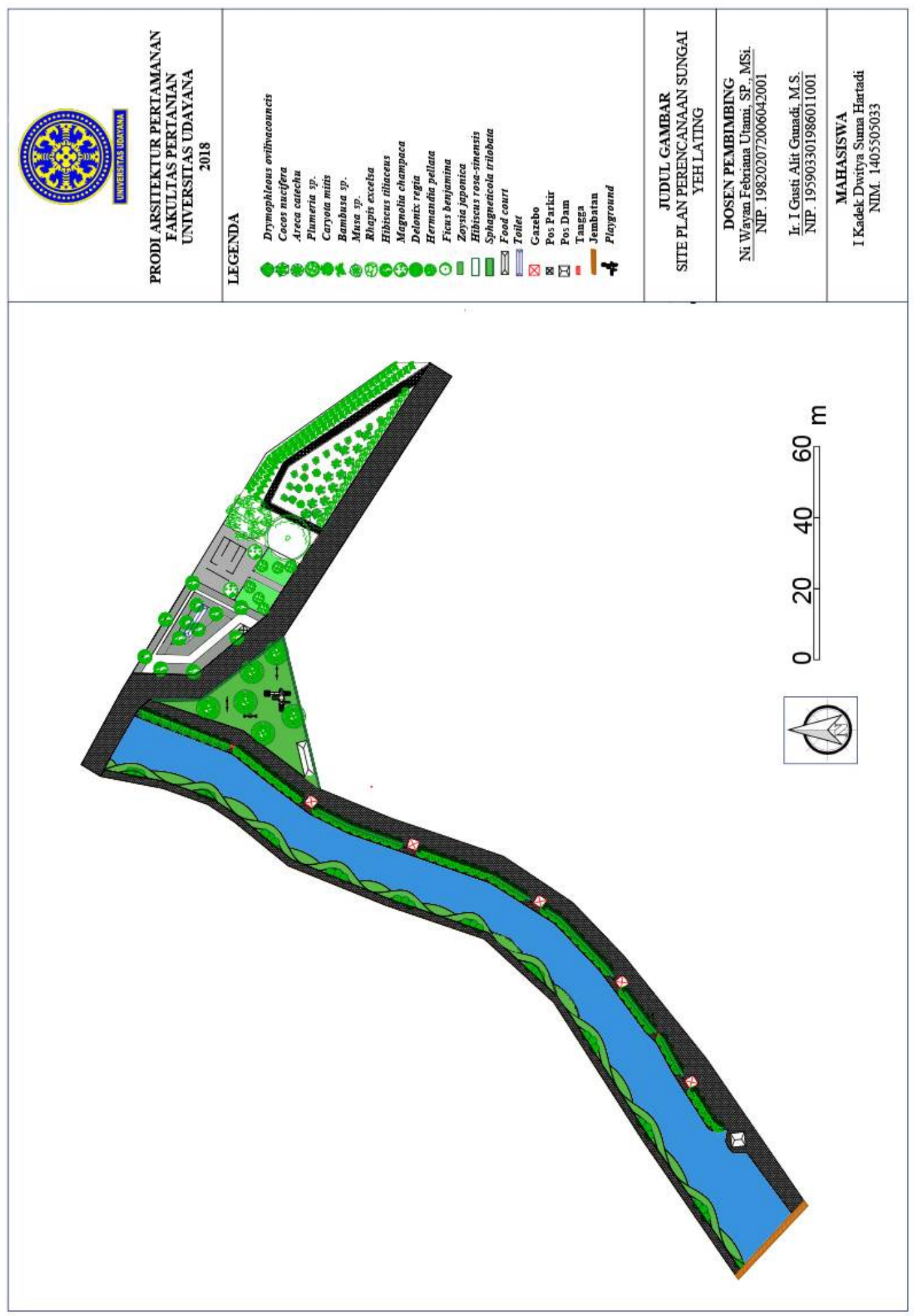

Gambar 5. Siteplan Sungai Yeh Lating 


\section{Simpulan dan Saran}

\subsection{Simpulan}

Potensi yang terdapat pada Sungai Yeh Lating di Desa Kerambitan antara lain akses yang mudah, fasilitas seperti bendung dan beji. Sedangkan permasalahan yang ditemui meliputi masalah fisik sempadan, kebersihan, penataan, dan kurangnya fasilitas seperti parkiran. Terdapat tanaman yang penanamannya tidak teratur sehingga mengurangi estetika. Tanah berlumpur saat hujan, dan belum tersedia fasilitas yang mendukung aktivitas masyarakat seperti belum tersedianya tempat parkir.

Konsep dasar yang digunakan adalah konsep kombinasi terasering pada subak dengan sungai kekinian. Mengadopsi terasering yang ada di Bali yang mencirikan Tabanan sebagai lumbung padi yang dikolaborasikan dengan sungai kekinian yang melambangkan pariwisata masa sekarang. Produk dari penelitian ini berupa konsep yang menghasilkan pembagian zona dan penataan (sirkulasi dan vegetasi) dengan hasil akhir berupa siteplan perencanaan Sungai Yeh Lating.

\subsection{Saran}

Hasil dari perencanaan Sungai Yeh Lating di kawasan Beji Arasiga Desa Kerambitan ini dapat menjadi refrensi alternatif bagi konsep pengembangan daerah penataan sempadan sungai dan dapat menjadi masukan bagi Pemda dalam masalah perencanaan sungai khususnya pada sempadan Sungai Yeh Lating di Desa Kerambitan.

\section{Daftar Pustaka}

Ali, M. 2014. Metodelogi dan Aplikasi Riset Pendidikan. Bumi aksara. Jakarta. 368p.

Badan Pusat Statistik. 2018. Nama Bendungan dan Kapasitasnya Dirinci Menurut Kabupaten/Kota di Provinsi Bali. Avaible online at: https://bali.bps.go.id//statictable/2018/04/10/52/nama-bendungan-dankapasitasnya-dirinci-menurut-kabupaten-kota-di-provinsi-bali-html

Bappeda Tk. II, 2015. RPJM Daerah Kabupaten Tabanan Tahun 2006-2010. Avaible online at: http://perpustakaan.bappenas.go.id//ontar/file?file=digital/13295-[Konten_-c4038.pdf . (accessed 10 Maret 2018)

Hartania, M. S., 2016. Provinsi Bali dalam Angka 2016. Avaible online at https://dlscrib.com/provinsi-balidalamangka-2016_58b648c76454a7ac11 b1e92e_txt.html. (accessed 10 September 2017)

Pemerintah Kabupaten Tabanan. 2016. Kerambitan Dalam Angka 2016. Badan Pusat Statistik Kab. Tabanan. Bali

Pemerintah Kabupaten Tabanan. 2018. Topografi. Avaible online at: https://www.tabanankab.go.id/page/4/ Topografi.html (accessed 28 februari 2018)

Simonds, J. O. and B. Starke. 2006. Landscape Architecture: A Manual of Land Planning and Design", 4th Edition. McGraw-Hill. New York. 396p. 